\title{
Vasopressin Regularizes the Phasic Firing Pattern of Rat Hypothalamic Magnocellular Vasopressin Neurons
}

\author{
Laurent Gouzènes, Michel G. Desarménien, Nicolas Hussy, Philippe Richard, and Françoise C. Moos \\ Centre National de la Recherche Scientifique-Unité Propre de Recherche 9055, Biologie des Neurones Endocrines, \\ Centre de Pharmacologie Endocrinologie, 34094 Montpellier cedex 05, France
}

\begin{abstract}
Vasopressin (AVP) magnocellular neurons of hypothalamic nuclei express specific phasic firing (successive periods of activity and silence), which conditions the mode of neurohypophyseal vasopression release. In situations favoring plasmatic secretion of AVP, the hormone is also released at the somatodendritic level, at which it is believed to modulate the activity of AVP neurons. We investigated the nature of this autocontrol by testing the effects of juxtamembrane applications of AVP on the extracellular activity of presumed AVP neurons in paraventricular and supraoptic nuclei of anesthetized rats. AVP had three effects depending on the initial firing pattern: (1) excitation of faintly active neurons (periods of activity of $<10 \mathrm{sec}$ ), which acquired or reinforced their phasic pattern; (2) inhibition of quasi-continuously active neurons (periods of silences of $<10$ sec), which became clearly phasic; and (3) no effect on neurons
\end{abstract}

already showing an intermediate phasic pattern (active and silent periods of 10-30 sec). Consequently, AVP application resulted in a narrower range of activity patterns of the population of AVP neurons, with a Gaussian distribution centered around a mode of $57 \%$ of time in activity, indicating a homogenization of the firing pattern. The resulting phasic pattern had characteristics close to those established previously for optimal release of AVP from neurohypophyseal endings. These results suggest a new role for AVP as an optimizing factor that would foster the population of AVP neurons to discharge with a phasic pattern known to be most efficient for hormone release.

Key words: vasopressin; autocontrol; phasic activity; optimization; supraoptic and paraventricular nuclei; extracellular electrical activity; hypothalamic magnocellular neurons
Most vasopressin (AVP) neurons in rat supraoptic nucleus (SON) and paraventricular nucleus (PVN) express a phasic activity characterized by a succession of periods of activity and silence. This specific pattern depends on intrinsic mechanisms as well as extrinsic factors such as plasma osmolarity, blood volume, and pressure (for review, see Poulain and Wakerley, 1982; Armstrong, 1995). During hyperosmotic stimulus or hemorrhage, AVP neurons either acquire or reinforce a phasic pattern (Brimble and Dyball, 1977; Poulain et al., 1977; Wakerley et al., 1978), which consequently increases systemic AVP release (for review, see Dyball, 1988). Hypo-osmotic stimulation has opposite effects, silencing AVP neurons in vitro (Oliet and Bourque, 1993a,b) and in vivo (Hussy et al., 1997). A supplementary control could be exerted by the peptide itself, similar to that described for oxytocin (OT) neurons, the stereotyped bursting activity of which depends on locally released OT during suckling (Moos and Richard, 1989; Lambert et al., 1993). Indeed, somatodendritic release of AVP has been demonstrated in both SON and PVN by morphological and pharmacological studies (Di Scala-Guenot et al., 1987; Pow and Morris, 1989; Ludwig et al., 1995). This local AVP release increases during osmotic stimulation and hemorrhage (Neumann et al., 1993; Ota et al., 1994), two physiological situations that

\footnotetext{
Received Oct. 1, 1997; revised Dec. 4, 1997; accepted Dec. 10, 1997.

We express our gratitude to David Brown for careful revision of this manuscript and judicious suggestions for the statistical analyses performed in this study. Our grateful thanks to Anne Duvoid and Pierre Fontanaud for their excellent technical assistance.

Correspondence should be addressed to Dr. Françoise C. Moos, Centre National de la Recherche Scientifique-Unité Propre de Recherche 9055 Biologie des Neurones Endocrines, Centre de Pharmacologie Endocrinologie-141, rue de la Cardonille, 34094 Montpellier cedex 05, France.

Copyright (c) 1998 Society for Neuroscience $\quad 0270-6474 / 98 / 181879-07 \$ 05.00 / 0$
}

favor the expression of phasic pattern in AVP neurons. Moreover, local application of AVP has been shown to modulate the activity of AVP neurons, although this effect is controversial. AVP has been reported to decrease (Leng and Mason, 1982; Abe et al., 1983), increase (Inenaga and Yamashita, 1986), or have no effect on the spontaneous firing (Carette and Poulain, 1989).

As an attempt to clarify the role of intranuclear AVP release on the firing rate and firing pattern of AVP neurons, in vivo extracellular recordings of these neurons were performed during juxtamembrane application of various concentrations of AVP, in male or lactating rats. We report that AVP favors the expression of phasic activity by presumed AVP neurons and homogenizes the characteristics of this pattern. A preliminary report of these results has appeared (Dayanithi et al., 1995).

\section{MATERIALS AND METHODS}

Experiments were performed on male or female lactating Wistar rats (Depré; 250-350 gm body weight). In the evening before the experiments, dams (8-12 d postpartum) were separated from all of their pups except one ( $\sim 14 \mathrm{hr}$ of separation). Rats were anesthetized with urethane (ethyl carbamate, $1.2 \mathrm{gm} / \mathrm{kg}$; Sigma) applied by a single intraperitoneal injection. A cannula was inserted into the jugular vein for intravenous injection of Brietal ( $9 \mathrm{mg} / \mathrm{kg}$; Lilly) to supplement anesthesia when necessary. In lactating rats, a thoracic mammary gland was cannulated and connected to an electromagnetic pressure transducer (Vigo-Spectramed, Oxnard, CA) to measure intramammary pressure peaks as an index of OT release. Suckling with 10 pups was applied 3 $\mathrm{hr}$ after anesthesia to trigger the milk ejection reflex (Lincoln et al., 1973). The rats were placed in a stereotaxic frame. Xylocaine (lydocaine hydrochloride, $1 \%$ solution; Rhône-Poulenc, Rohrer, France) was injected subcutaneously to all surgical sites and at the points of contact with the stereotaxic frame. After trepanning, a bipolar stimulating electrode was inserted into the pituitary stalk at the limit of the neurohypophysis (Anteriority, (A), 4.7; Laterality, (L), 0; Height, (H), 0.5; stereotaxic atlas of Albe-Fessard et al., 1966) for antidromic 


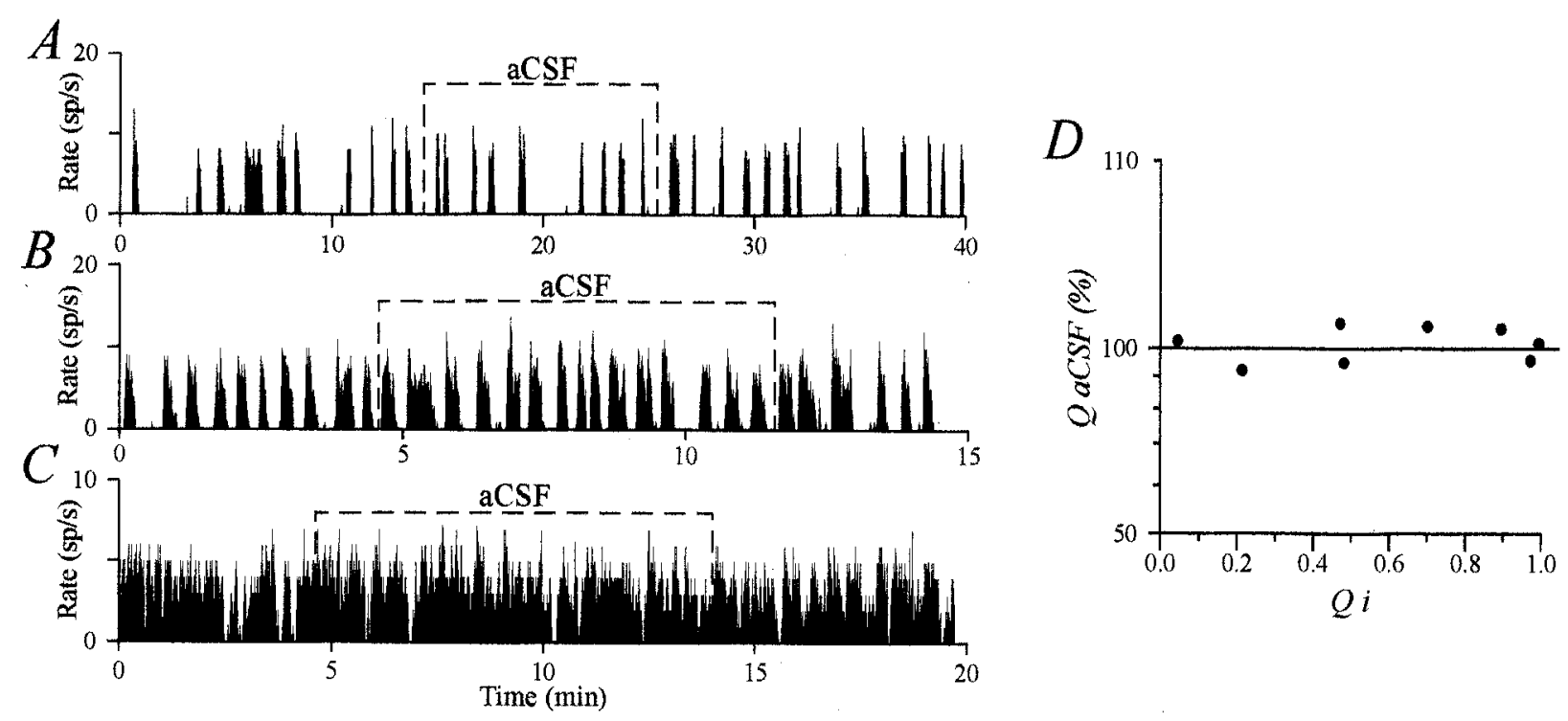

Figure 1. Control application of aCSF did not affect firing of vasopressin neurons. $A-C$, aCSF application on AVP neurons displaying different phasic patterns did not change their characteristics of discharge. $D$, The activity quotient during aCSF application $\left(Q_{\mathrm{aCSF}}\right.$ in percent) was plotted against initial values $\left(Q_{\mathrm{i}}\right)$. In no case did aCSF application affect the firing pattern.

identification of magnocellular neurons (SON or PVN neurons). The exact position of the electrode was attested (1) in lactating rats by a peak of intramammary pressure evoked by repetitive electrical stimulation of the pituitary stalk ( $40 \mathrm{~Hz}, 0.3-0.5 \mathrm{~mA}, 0.5 \mathrm{msec}$ for $4 \mathrm{sec})$, and (2) in male rats by a posteriori observation of the site of lesion provoked by electrolytic current (10 mA during a few seconds). Recording glass micropipettes filled with $0.5 \mathrm{M}$ sodium acetate solution (8-20 M $\Omega$ impedance) were placed in the SON (A, 7-8; L, 1-2.3; H, 2.5-2) or PVN (A, 6.5-7; L, 0.1-0.7; H, 4-3.5) and connected to conventional electrophysiological apparatus. Extracellular electrical activities were displayed on a chart recorder (Astromed SNC, Trappes, France) and simultaneously stored on computer by means of a Cambridge Electronic Design (Cambridge, UK) 1401 interface card. Juxtamembrane injections of AVP close to the recorded neuron were performed using a glass micropipette glued 20-40 $\mu \mathrm{m}$ above the recording micropipette and connected to a pneumatic picopump (W PI Inc., Sarasota, FL). Nitrogen pressure was adjusted to $0.7-1.4$ bars according to the tip diameter of the pressure micropipette $(10-20 \mu \mathrm{m})$, and drugs were delivered by applying pressure pulses of $10-30 \mathrm{msec}$ with a square waveform repeated every $1-10 \mathrm{sec}$ over periods of 2-15 min. Calibration of ejection pulses performed under microscopic observation revealed that the total volume ejected for each application varied between 20 and $100 \mathrm{nl}$. Because the pipette tip could be partly occluded by the tissue while it was lowered through the brain, the volume applied was possibly less than estimated. The outflow from the pressure pipette was checked under binocular observation before and after each recording.

AVP (Boehringer Mannheim, Meylan, France) was used at three concentrations $(0.1,1$, and $10 \mu \mathrm{M})$ in artificial CSF (aCSF, in mM: $\mathrm{NaCl}$, 126.5; $\mathrm{NaHCO}_{3}, 27.5 ; \mathrm{KCl}, 2.4 ; \mathrm{KH}_{2} \mathrm{PO}_{4}, 0.5 ; \mathrm{CaCl}_{2}, 1.1 ; \mathrm{MgCl}_{2}, 0.83$; and $\mathrm{Na}_{2} \mathrm{SO}_{4}, 0.5$ with glucose, $5.9 \mathrm{~g} / \mathrm{l}$ ). The $\mathrm{pH}$ was adjusted to 7.4 , and osmolarity was $300 \pm 2 \mathrm{mOsm} / \mathrm{l}$. Because of variability of the injection parameters used in each experiment, the drug concentration seen by each neuron tested can differ.

Identification of neurons and data analysis. The magnocellular neurons were identified by their antidromic response to electrical stimulation of the neurohypophysis (the response had a constant latency, followed high frequency stimulation, and collided with an orthodromic spike). Presumed AVP neurons, in male or lactating rats, were in most cases characterized by their phasic activity comprising distinct periods of activity separated by periods of silence (Fig. $1 A, B$ ), were also considered putative AVP neurons, those that fired quasi-continuously (long periods of activity separated by silences of $<10 \mathrm{sec}$; Fig. $1 C$, also see Fig. $3 A$ ), or that were quasi-silent (periods of activity of $<10 \mathrm{sec}$; Fig. $2 A$ ) but that responded to AVP by the appearance of a phasic activity. Because (1) phasic activity is a major characteristic of AVP neurons (for review, see
Armstrong, 1995), (2) only AVP neurons have been shown to possess AVP receptors (Berlove and Piekut, 1990; Dayanithi et al., 1995), (3) all OT neurons identified by milk ejection-related activity were found insensitive to AVP, and (4) none of the 21 AVP-sensitive phasic neurons recorded from lactating rats during suckling showed milk ejection bursts, we will refer to the phasic neurons recorded in this study as AVP neurons. OT neurons displayed a random continuous basal activity, over which, in lactating rats during the milk ejection reflex, a characteristic periodic bursting activity developed. The latter consisted of an intense and brief activation 12-18 sec before each milk ejection (attested by a peak of intramammary pressure or by a stretch reaction of the pups). On some occasions, OT (1 ng, i.e., $1 \mu \mathrm{l}$ of $1 \mu \mathrm{M}$ solution in $0.9 \% \mathrm{NaCl}$; Sandoz, Basel, Switzerland) was injected into the third ventricle (A, 8; L, $0 ; \mathrm{H}, 3$ ) to induce or facilitate bursting activity (Freund-Mercier and Richard, 1984). In other cases, a hyperosmotic stimulation was applied (2 $\mathrm{ml}$ of $1.5 \mathrm{M} \mathrm{NaCl}$ solution, i.p.) to induce specific tonic activation of OT neurons (Wakerley et al., 1978).

Analysis of the electrophysiological recordings was performed using both in-house programs and Spike2 analysis software (Cambridge Electronic Design). The firing pattern of AVP neurons was analyzed for 15-20 min before (control period) and during the entire application of AVP. This pattern was characterized by the following parameters: (1) $f$, the mean firing rate during periods of activity called "intraburst frequency" (in spikes/sec); (2) da, the duration of active periods (in sec); (3) $d s$, the duration of silent periods (in sec); and (4) $Q$, the proportion of time spent by a phasic cell during burst (calculated by exclusion of silent periods of $>2 \mathrm{sec}$ ). This latter parameter is equivalent to the activity quotient described by Wakerley et al. (1975). For OT neurons recorded during suckling, the parameters considered were (1) the background activity (in spikes/sec) and (2) the burst amplitude (total number of spikes per burst). AVP was considered to affect the firing pattern of AVP or OT neurons when changes in parameters exceeded $10 \%$ of control values. Indeed, during 5-10 min applications of aCSF, the changes that occurred in the firing characteristics of eight AVP (Fig. $1 A-C$ ) and five OT neurons (data not shown; see Moos et al., 1997) were always $<10 \%$. This is illustrated for AVP neurons in Figure $1 D$, in which the $Q$ value measured during aCSF microinjection (and expressed as a percentage of the initial $Q, Q_{\mathrm{i}}$ ) is plotted as a function of $Q_{\mathrm{i}}$. For OT bursting neurons, the mean firing rate and burst amplitude were similar during control period and aCSF application $(3.0 \pm 0.6$ and $3.0 \pm 0.6$ spikes/sec; $69 \pm 12$ and $69 \pm 12$ spikes, respectively). All values are expressed as mean \pm SEM. Statistical significance was assessed by different tests indicated in Results. Curve fitting was performed with Origin software (Microcal Software). 


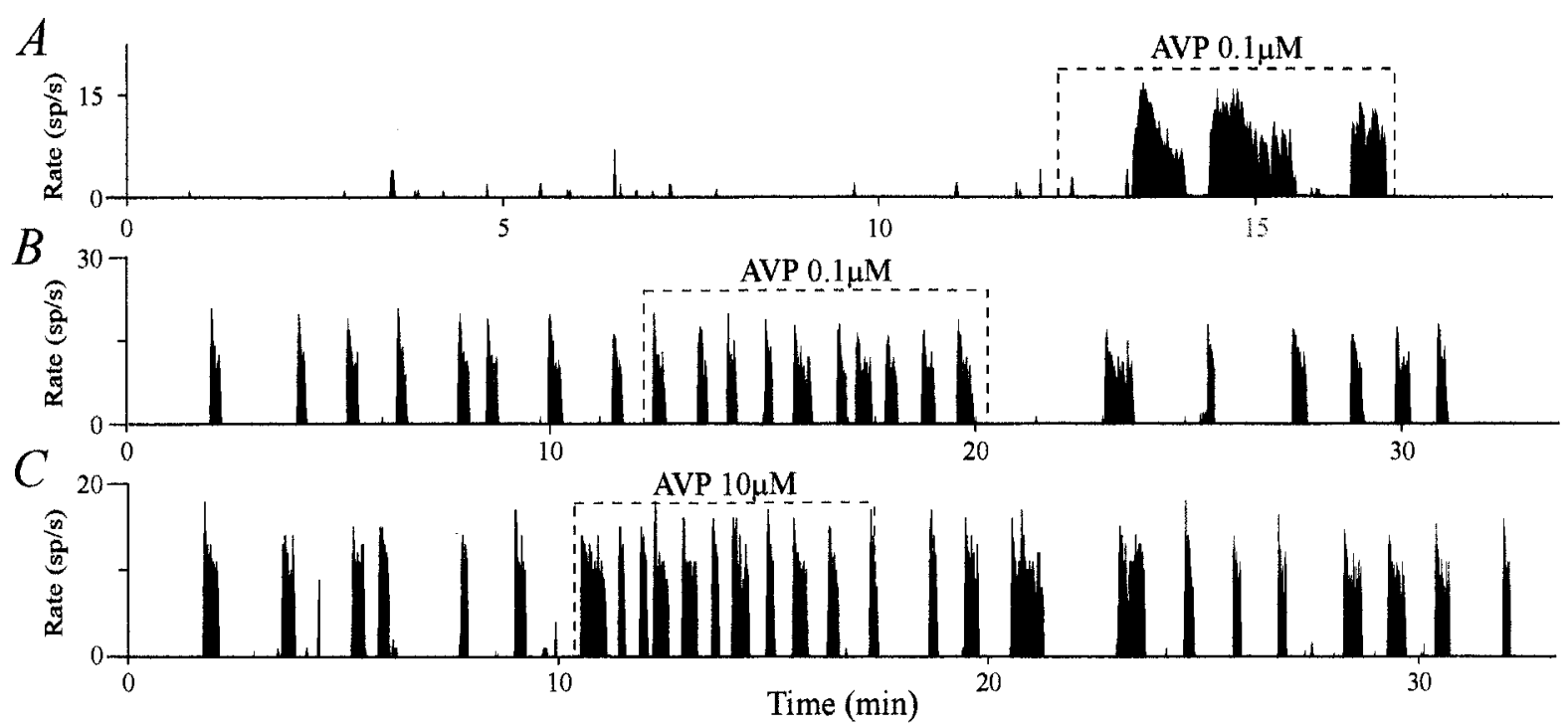

Figure 2. Excitatory effect of AVP on the firing pattern of some AVP neurons. A, AVP triggered phasic firing in quasi-silent neurons. On clearly phasic neurons displaying short periods of activity, AVP induced an increase in burst duration and a decrease in the duration of silences $(B, C)$. This effect was accompanied with a slight decrease $(B)$, an increase $(A)$, or no effect in the intraburst frequency $(C)$.

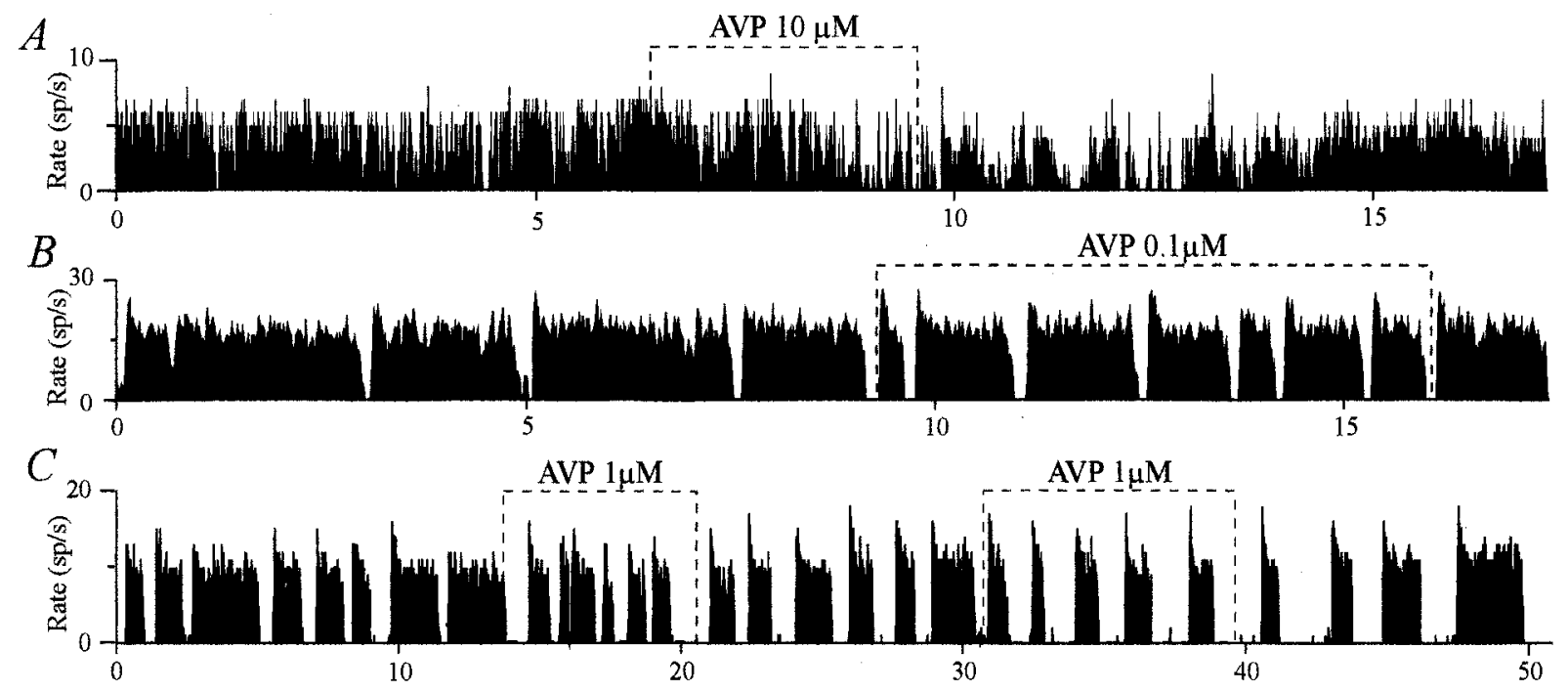

Figure 3. Inhibitory effect of AVP on the firing pattern of some AVP neurons. AVP depressed firing of a quasi-continuously active neuron (decrease in intraburst frequency), which progressively acquired a phasic pattern $(A)$. AVP inhibited the phasic pattern by decreasing the duration of active periods $(B)$ or increasing the duration of silences $(C)$. In $C$, this effect outlasted the duration of application, was more pronounced during the second test, and was accompanied by an increase in intraburst frequency.

\section{RESULTS}

\section{Effect of AVP on AVP neurons}

Recordings were obtained from 39 AVP neurons in either the SON $(n=26)$ or PVN $(n=13)$ from 14 rats. Three concentrations of AVP were applied, 0.1, 1, and $10 \mu \mathrm{M}$ on, respectively, 9, 8, and 22 AVP neurons that displayed different patterns of discharge (phasic, quasi-continuously active, or quasi-silent neurons). Three different effects of AVP on the firing pattern were observed: excitatory (Fig. 2), inhibitory (Fig. 3), or no effect (Fig. 4 ), and these were observed on both PVN and SON neurons. Changes induced by AVP were sustained and reversible with a return to control parameter values within 5-10 min after the end of the application, independently of the dose of AVP or the duration of the application. Because no difference could be detected related to the concentration of AVP applied (see below), all results were pooled.

An excitatory effect was observed for 17 neurons. Nine were quasi-silent before AVP application and acquired a phasic pattern of activity (Fig. $2 A$ ) with a mean $d a$ of $34 \pm 8 \mathrm{sec}$ and a mean $d s$ of $19 \pm 5 \mathrm{sec}$. For eight initially phasic neurons, there was an increase in $d a$ (from $15 \pm 4$ to $20 \pm 3 \mathrm{sec}$ ) and a decrease in $d s$ (from $58 \pm 7$ to $28 \pm 6 \mathrm{sec}$ ) (Fig. $2 \mathrm{~B}, \mathrm{C}$ ). Both excitatory effects were characterized by an increase in the activity quotient $Q$ (from $0.11 \pm 0.02$ to $0.58 \pm 0.04 ; n=17$ ). Conversely, AVP had an inhibitory effect on the activity of 15 neurons. Eight were initially quasi-continuously active neurons and acquired a phasic pattern 


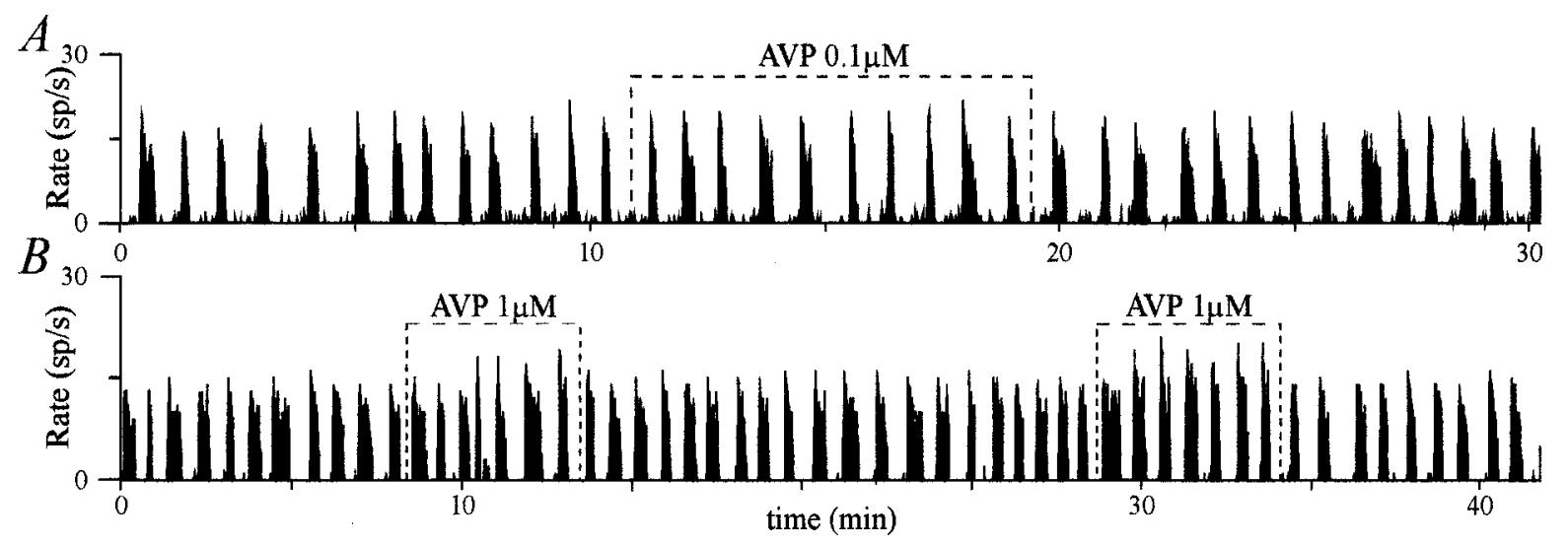

Figure 4. AVP did not affect the firing pattern of some clearly phasic AVP neurons. AVP applied on clearly phasic neurons did not affect their firing pattern $(A, B)$. Note that in $B$, AVP slightly increased the intraburst frequency, an effect more pronounced during the second application.
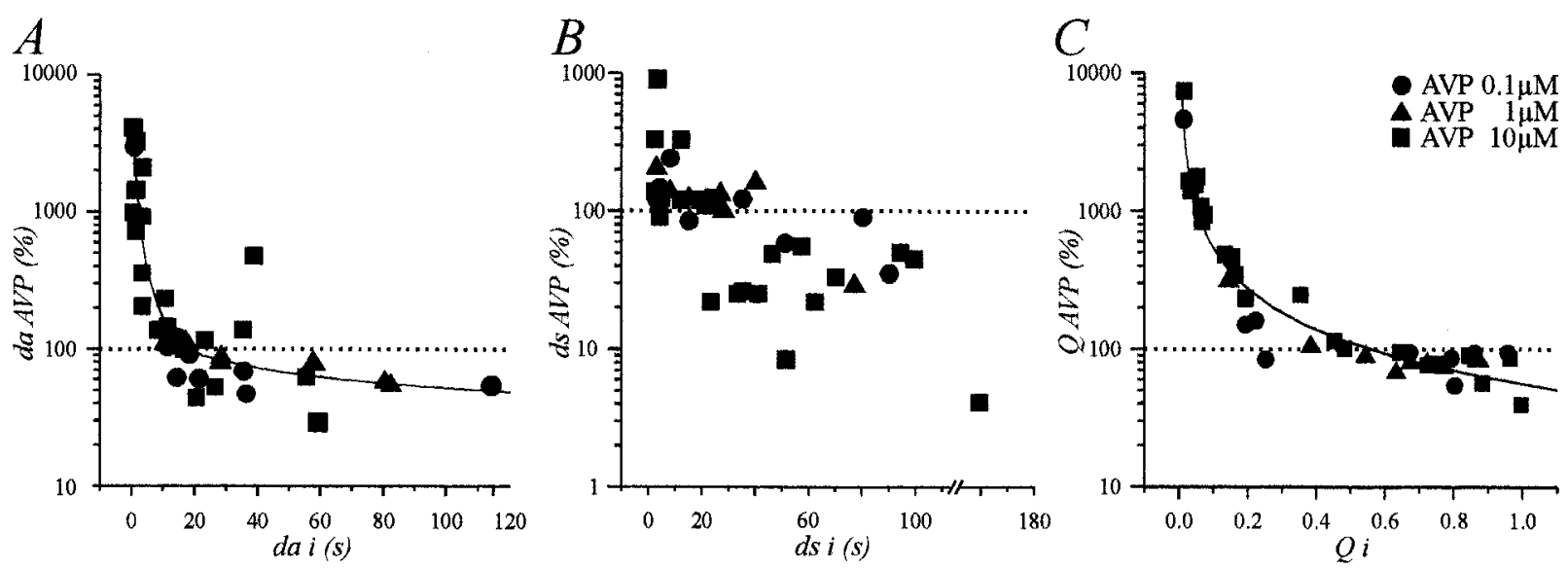

Figure 5. Relationships between the effects of AVP and the initial firing pattern. The duration of active periods, the duration of silent periods, and the activity quotient measured during the application of $\operatorname{AVP}\left(d a_{\mathrm{AVP}}, d s_{\mathrm{AVP}}\right.$, and $Q_{\mathrm{AVP}}$, respectively $)$ are expressed as a percentage of their respective initial values $\left(d a_{\mathrm{i}}, d s_{\mathrm{i}}\right.$, and $\left.Q_{\mathrm{i}}\right)$ and plotted as a function of $d a_{\mathrm{i}}, d s_{\mathrm{i}}$, and $Q_{\mathrm{i}}$ on semilogarithmic scales. In $A$ and $C$, lines are apparent linear regressions fitted with 38/39 data points initially plotted on a $\log / \log$ scale. These fits indicate significant relationships between $d a_{\mathrm{AVP}}$ and $d a_{\mathrm{i}}$ and $Q_{\mathrm{AVP}}$ and $Q_{\mathrm{i}}$. Fits cross the $100 \%$ line at $18 \mathrm{sec}(d a)$ and $0.56(Q)$.

during the application (Fig. $3 A$ ), with $d a=23 \pm 7 \mathrm{sec}$ and $d s=$ $9 \pm 2$ sec. For seven initially clearly phasic neurons, inhibition consisted in a decrease in $d a$ (from $44 \pm 8$ to $32 \pm 5 \mathrm{sec}$ ) and an increase in $d s$ (from $19 \pm 4$ to $30 \pm 6 \mathrm{sec}$ ) (Fig. $3 B, C$ ). These inhibitory effects resulted in a decreased $Q$ (from $0.81 \pm 0.03$ to $0.61 \pm 0.04 ; n=15)$. AVP had no effect on seven neurons, all showing clear phasic activity (Fig. 4). AVP affected neither $d a$ nor $d s(d a, 19 \pm 2$ vs $20 \pm 4 \mathrm{sec} ; d s, 23 \pm 4$ vs $21 \pm 4 \mathrm{sec})$, and consequently, $Q$ was equivalent before and during AVP application $(0.47 \pm 0.05$ vs $0.49 \pm 0.05)$. Strikingly, it appeared from these observations that the nature of the AVP effects was related to the characteristics of the initial pattern of activity of the neurons. Indeed, AVP seemed to excite mostly neurons with low initial activity, to inhibit mostly neurons with a high initial activity, and not to affect those displaying an intermediate phasic activity.

To characterize this dependence on the initial pattern of activity, we expressed the values of $d a, d s$, and $Q$ measured in the presence of $\operatorname{AVP}\left(d a_{\mathrm{AVP}}, d s_{\mathrm{AVP}}\right.$, and $\left.Q_{\mathrm{AVP}}\right)$ as a function of their initial value $\left(d a_{\mathrm{i}}, d s_{\mathrm{i}}\right.$, and $Q_{\mathrm{i}}$; Fig. 5). Changes in $d a, d s$, and $Q$ were clearly inversely related to $d a_{\mathrm{i}}, d s_{\mathrm{i}}$, and $Q_{\mathrm{i}}$ (Fig. 5). For $d a$ and $Q$, an apparent linear regression could be fitted when the data were plotted on a double logarithmic scale, which indicated that the values of $d a_{\mathrm{i}}$ and $Q_{\mathrm{i}}$ for which AVP had no effect were $18 \mathrm{sec}$ (Fig. 5A) and 0.56 (Fig. 5C), respectively. The relationship between $d s_{\mathrm{AVP}}$ and $d s_{\mathrm{i}}$ was evident, but the distribution prevented a satisfying fit of the data. However, it clearly appeared that $d s_{\mathrm{i}}$ values $>30 \mathrm{sec}$ tended to be decreased, whereas those $<10 \mathrm{sec}$ tended to be increased. We then compared the mean $Q_{\mathrm{i}}$ of neurons excited by $\operatorname{AVP}\left(Q_{\mathrm{i}}=0.11 \pm 0.02 ; n=17\right)$ and of those inhibited $\left(Q_{\mathrm{i}}=0.81 \pm 0.03 ; n=15\right)$. Student's $t$ tests revealed a significant difference at $p<0.001$, indicating that these neurons belonged to different populations. Furthermore, both $Q_{\mathrm{i}}$ values differed significantly from $0.50(p<0.001)$, a value corresponding to the mean $Q_{\mathrm{i}}$ of neurons that were unaffected $(0.49 \pm 0.05 ; n=$ 7). We also compared the effect of AVP on neurons now categorized in three equivalents groups according to their $Q_{\mathrm{i}}\left(Q_{\mathrm{i}} \leq 0.33\right.$; $0.33<Q_{\mathrm{i}} \leq 0.66 ; Q_{\mathrm{i}}>0.66$; Fig. $\left.6 A\right)$. Low $Q_{\mathrm{i}}(0.11 \pm 0.02, n=$ $17)$ were significantly increased by AVP to a mean value of $0.54 \pm$ $0.04(p<0.001$, Student's paired $t$ test $)$. High $Q_{\mathrm{i}}(0.82 \pm 0.03 ; n=$ $15)$ was decreased to $0.63 \pm 0.04(p<0.01)$, and intermediate $Q_{\mathrm{i}}$ $(0.50 \pm 0.04, n=7)$ was unaffected $(0.54 \pm 0.06)$. Last, we looked at the effect of AVP on the distribution of $Q$ values. Whereas there was no significant difference between the averaged values of 

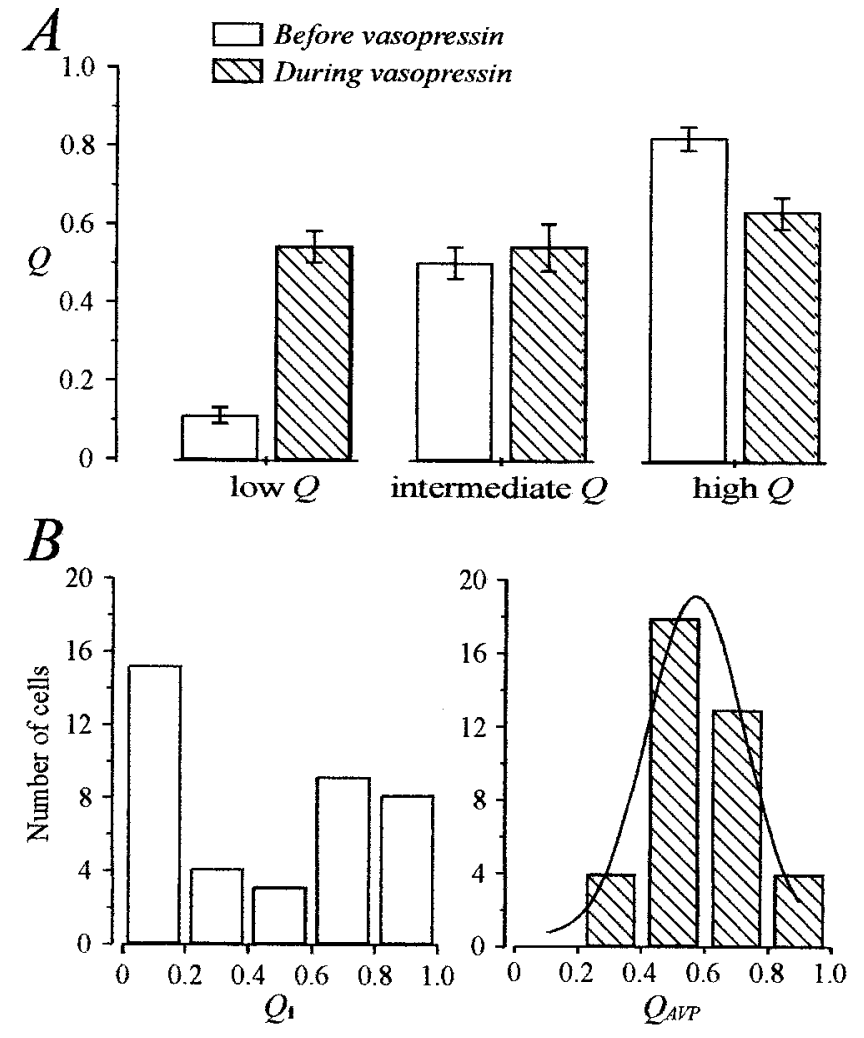

Figure 6. Changes in the activity quotient induced by AVP. A, Effects of AVP on neurons classified in three categories according to their $Q_{\mathrm{i}}$ (limits, 0.33 and 0.66). AVP brought the neurons to fire with an intermediate $Q$ of $\sim 0.50-0.60$. $B$, Distribution of AVP neurons $(n=39)$ according to their activity quotient before $\left(Q_{\mathrm{i}}\right)$ and during $\operatorname{AVP}\left(Q_{\mathrm{AVP}}\right)$ application. AVP narrowed the distribution of $Q$, which became normal and was well fitted with a Gaussian curve around a mode value of 0.57 .

$Q_{\mathrm{i}}(0.45 \pm 0.05)$ and $Q_{\mathrm{AVP}}(0.57 \pm 0.03 ; n=39 ; p>0.05)$, the variance of $Q_{\mathrm{AVP}}$ was reduced by greater than four times (from 0.112 to 0.026 ). Indeed, as shown in Figure $6 B$, although the values of $Q_{\mathrm{i}}$ were spread out over the entire range, AVP induced the distribution of $Q$ to become normal, being fitted with a Gaussian curve with a mode of $0.57 \pm 0.02$ and an SD of 0.12.

AVP had different effects on the intraburst frequency, $f$, which was enhanced (Figs. $2 A, 4 B$ ), decreased (Fig. $3 A$ ), or unaffected (Figs. $2 C, 3 B, 4 A$ ) at all concentrations tested. The excitatory effect was observed in $46 \%$ of the neurons recorded (from $4.7 \pm$ 1.0 to $6.6 \pm 1.0 \mathrm{spikes} / \mathrm{sec})$. AVP had no effect in $44 \%$ of the neurons $(6.8 \pm 1.0$ vs $6.7 \pm 1.0$ spikes $/ \mathrm{sec}$ ) and decreased $f$ (from $10.4 \pm 1.1$ to $7.7 \pm 1.6$ spikes/sec) in the remaining neurons $(10 \%)$. The effects of AVP on $f$ were not related to the initial firing characteristics or to the changes in the pattern induced by AVP (Figs. 2-4).

\section{Effect of AVP on OT neurons}

Application of AVP (0.1, 1, and $10 \mu \mathrm{M} ; 100-300 \mathrm{sec})$ did not change the firing rate of OT neurons $(3.8 \pm 1.2,3.9 \pm 0.9$, and $3.6 \pm 0.8$ spikes/sec before, during, and after application of AVP, respectively; $n=7$ ). Furthermore, the bursting pattern (either spontaneous or facilitated by OT; $n=4$; Fig. $7 A$ ) and the tonic activation induced by systemic injection of hyperosmotic saline $(n=3$; Fig. $7 B)$ were not affected by AVP.

\section{DISCUSSION}

In the present work, vasopressin was applied onto magnocellular presumed AVP neurons to clarify its role in the control of their electrical activity. The responses observed were attributable to AVP and not to nonspecific mechanical perturbations, as attested by the lack of effect of aCSF application. This suggests that our local pressure microinjections allow the drug to diffuse gently around the neurons without creating deformation of brain tissue. Furthermore, the ineffectiveness of AVP to affect OT neurons, which like AVP neurons possess mechanoreceptors (Oliet and Bourque, 1993a,b), attests to the specificity of the effects of AVP on AVP neurons.

AVP had different effects on the activity pattern of AVP neurons: excitatory, inhibitory, or no effect. Qualitatively similar responses were obtained with the three doses of AVP tested, and no correlation could be found between the magnitude of the effect and the AVP concentration. The absence of dose dependency may result from an already high level of activation of AVP receptors by the lowest concentration used $(0.1 \mu \mathrm{M}$; see Dayanithi et al., 1996). On the other hand, these effects remarkably depended on the initial activity pattern. Indeed, AVP excited neurons displaying a low activity quotient, triggering or enhancing phasic activity, and inhibited highly active neurons; phasic neurons initially displaying intermediate $Q$ were not affected. Consequently, by reducing the proportion of neurons displaying very low and very high activity, AVP narrowed the distribution of $Q$, which became normal, at a mode of $\sim 0.57$. Therefore, application of AV P resulted in the homogenization of the firing pattern of the whole population of AVP neurons. This mean intermediate phasic pattern was characterized by a duration of active periods $(d a)$ of $\sim 20 \mathrm{sec}$ and duration of silences $(d s)$ of 10-30 sec. With regard to the intraburst frequency, $f, \mathrm{AVP}$ also had different effects, but they were unrelated to the initial pattern of activity. So, AVP regulated the phasic pattern and firing rate differently and independently.

\section{Inhibitory and excitatory role of AVP}

As far back as 1981, Leng had already speculated that AVP could modulate the phasic pattern of AVP neurons in rats. Thereafter, using extracellular recordings from rat hypothalamic slices, AVP has been shown to modify the firing pattern of SON or PVN neurons, but different reports are contradictory; according to Inenaga and Yamashita (1986), AVP had an excitatory effect on the firing rate of unidentified PVN neurons, whereas Leng and Mason (1982) reported that AVP inhibited the phasic pattern of AVP neurons in SON from Brattleboro rats. By intracellular recordings on guinea pig hypothalamic slices, Carette and Poulain (1989) observed that application of AVP did not affect AVP phasic neurons but depolarized neighboring interneurons projecting onto AVP neurons. Finally, Abe et al. (1983) reported that AVP depolarized the membrane but decreased the spontaneous firing rate in most neurons tested $(\sim 69 \%)$, the others being either excited $(\sim 5 \%)$ or unaffected $(\sim 26 \%)$. However, when AVP was applied to a previously hyperpolarized neuron, the inhibitory effect on firing was reversed to excitatory in both spontaneously active and silent neurons. In agreement with this observation, dissociated SON neurons, which display no or little spontaneous activity (M.G. Desarménién, personal observation), respond to AVP by an influx of calcium through voltage-dependent calcium channels, attesting for an excitatory effect of AVP (Dayanithi et al., 1996; Sabatier et al., 1997). The resulting increase in intracellular calcium concentration could modulate the phasic pattern of 

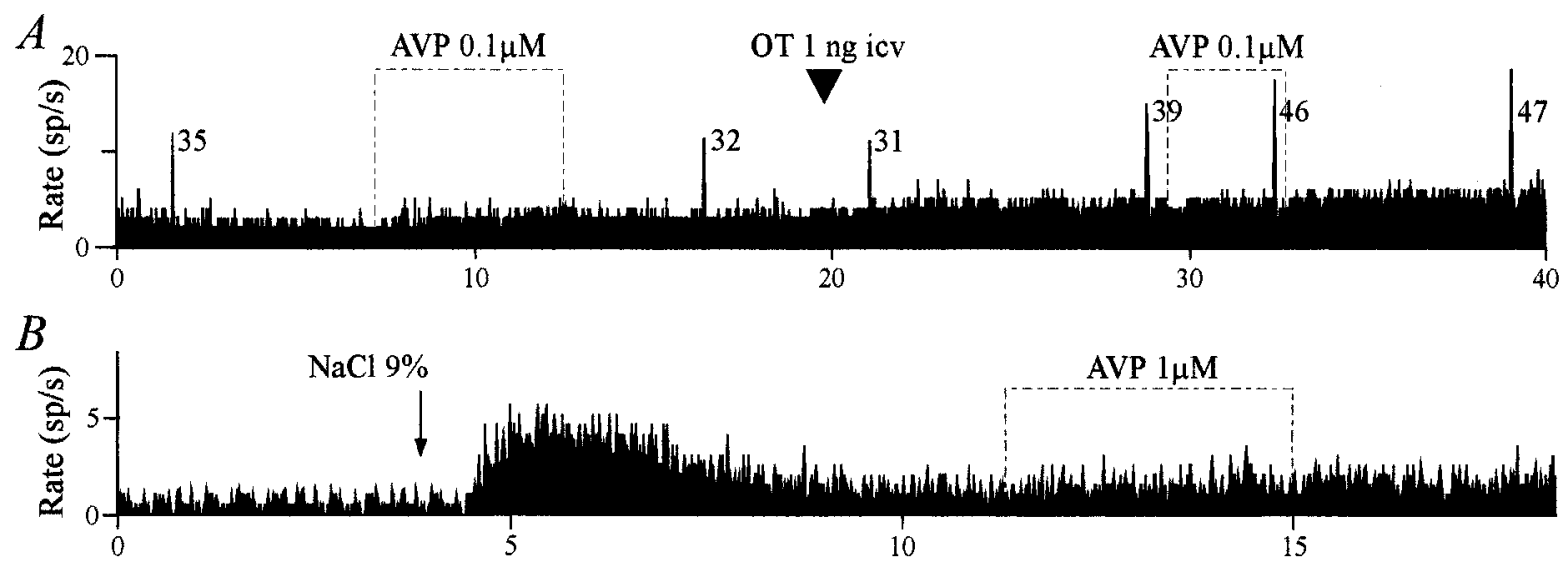

Figure 7. Lack of effect of AVP on OT neurons. A, AVP did not affect the basal activity or the bursting pattern of an OT neuron recorded during the milk ejection reflex, whether the reflex was facilitated by an intracerebroventricular injection of $1 \mathrm{ng}$ of OT. The number beside each burst indicates the total number of spikes in that burst. $B$, AVP applied on a putative OT neuron did not modify the tonic activation induced by a systemic hyperosmotic stimulus $(2 \mathrm{ml}$ of $9 \% \mathrm{NaCl}$, i.p.).

AVP neurons (Bourque, 1986; Andrew, 1987; Inenaga et al., 1992; Li and Hatton, 1995, 1997). This suggests that the inhibitory and excitatory effect of AVP could depend on the initial level of membrane polarization, which itself is known to influence the firing pattern (Andrew and Dudek, 1984). Such a hypothesis is corroborated by the present work showing that AVP exerted inhibitory, excitatory, or no effect on AVP neurons according to their initial pattern of discharge.

\section{AVP favors a phasic activity optimizing the neurohypophyseal AVP release}

Previous in vitro experiments using freshly isolated rat neurohypophyses impaled onto a stimulating electrode have established a relationship between the activity pattern, the firing rate, and the release of AVP. Dutton and Dyball (1979) have demonstrated that stimulating the neurosecretory tissue with a phasic pattern optimizes AVP release from nerve endings. Thereafter, it was shown that most of the release of AVP from the neurohypophysis occurs during the first $20 \mathrm{sec}$ of activity (Bicknell et al., 1984; Shaw et al., 1984), and interruption of firing of $>20 \mathrm{sec}$ dramatically enhances systemic release of AVP (Cazalis et al., 1985). These values are close to the values of $d a$ and $d s$ found in this study. With regard to $f$, the values measured during AVP application remain in the range of frequency known to be most efficient for the release of AVP from neurohypophysis in vitro, i.e., frequency of $\geq 6$ pulses/sec (Dutton and Dyball, 1979). Consequently, the changes in $f$ induced by AVP are likely to have less influence on the systemic release of AVP than those in the activity pattern, as suggested already by Poulain et al. (1988). Therefore, AVP released intranuclearly in cases of high hormonal need may be considered as optimizer of the phasic activity pattern of AVP neurons, which is a major determinant of the amount of AVP released from the neurohypophysis. Interestingly, although different in nature, the role of intranuclear OT is also to facilitate a neuronal behavior optimum for hormonal function, i.e., the suckling-induced synchronous bursting activity (Moos and Richard, 1989; Lambert et al., 1993). This control is specific to OT, because AVP is ineffective (Freund-Mercier and Richard, 1984; present data). Thus, the two populations of magnocellular neurons display specific rhythmic patterns of discharge, which are controlled and fostered by their respective peptide.

\section{Physiological meaning}

Using a dual immunocytochemical labeling procedure, it has been shown that AVP receptor sites are associated with AVPcontaining neurons in SON and PVN (Berlove and Piekut, 1990). Through these autoreceptors, the activity of AVP neurons could be modulated by AVP released somatodendritically (Neumann et al., 1993) or by the connections between AVP neurons within the SON (Leng and Wiersma, 1981). These effects could be complemented by a presynaptic action of AVP on afferent terminals, as recently suggested by Kombian et al. (1997), or a recurrent action via neighboring interneurons projecting onto magnocellular neurons (Leng and Dyball, 1983). This modulatory role would be particularly prominent in physiological situations in which local AVP release is increased, e.g., during hyperosmotic stimulation (Neumann et al., 1993) and hemorrhage (Ota et al., 1994). The intranuclear release of AVP in response to these stimuli has been shown to be maintained for several hours (Ludwig et al., 1994). One would then expect sustained modulatory effects of AVP on the firing of AVP neurons. This should allow the expression of a phasic pattern of discharge that would be optimal for a sustained systemic AVP release, in accordance to the physiological demand. Interestingly, a former study has reported that 6-18 hr dehydration induced $80-100 \%$ of AVP neurons to fire phasically with mean burst duration between 20 and $24 \mathrm{sec}$ and mean silence duration between 13 and $17 \mathrm{sec}$ (Wakerley et al., 1978).

In conclusion, the present work shows that local AVP favors the expression by AVP neurons of a specific phasic activity known to optimize the systemic release of AVP. This reveals a new concept of modulation of neuronal activity by centrally released peptides: the optimization of a neuronal discharge in accordance with the physiological demand.

\section{REFERENCES}

Abe H, Inoue M, Matsuo T, Ogata N (1983) The effects of vasopressin on electrical activity in the guinea pig supraoptic nucleus in vitro. J Physiol (Lond) 337:665-685.

Albe-Fessard D, Libouban S, Stutinsky F (1966) Atlas stéréotaxique du diencéphale du rat blanc. Paris: Centre National de la Recherche Scientifique.

Andrew RD (1987) Endogenous bursting by rat supraoptic neuroendocrine cells is calcium dependent. J Physiol (Lond) 384:451-465.

Andrew RD, Dudek FE (1984) Analysis of intracellularly recorded pha- 
sic bursting by mammalian neuroendocrine cells. J Neurophysiol 51:552-566.

Armstrong WE (1995) Morphological and electrophysiological classification of hypothalamic supraoptic neurons. Prog Neurobiol 47:291-339.

Berlove DJ, Piekut DT (1990) Co-localization of putative vasopressin receptors and vasopressinergic neurons in rat hypothalamus. Histochemistry 94:653-657.

Bicknell RJ, Brown D, Chapman C, Hancock PD, Leng G (1984) Reversible fatigue of stimulus-secretion coupling in the rat neurohypophysis. J Physiol (Lond) 348:601-613.

Bourque CW (1986) Calcium-dependent spike after-current induces burst firing in magnocellular neurosecretory cells. Neurosci Lett 70:204-209.

Brimble MJ, Dyball REJ (1977) Characterization of the responses of oxytocin- and vasopressin-secreting neurones in the supraoptic nucleus to osmotic stimulation. J Physiol (Lond) 271:253-271.

Carette B, Poulain P (1989) Vasopressin-sensitive neurons in the lateral paraventricular nucleus area in a guinea pig slice preparation. Brain Res Bull 22:969-974.

Cazalis M, Dayanithi G, Nordmann JJ (1985) The role of patterned burst and interburst interval on the excitation-coupling mechanism in the isolated rat neural lobe. J Physiol (Lond) 369:45-60.

Dayanithi G, Moos F, Richard PH (1995) Vasopressin controls magnocellular vasopressin neurones via $\mathrm{V}_{1}$-type receptors in the rat. $\mathrm{J}$ Physiol (Lond) 489:184-185.

Dayanithi G, Widmer H, Richard PH (1996) Vasopressin-induced intracellular $\mathrm{Ca}^{2+}$ increase in isolated rat supraoptic cells. J Physiol (Lond) 490:713-727.

Di Scala-Guenot D, Strosser MT, Richard PH (1987) Electrical stimulations of perifused magnocellular nuclei in vitro elicit $\mathrm{Ca}^{2+}$ dependent, tetrodotoxin-insensitive release of oxytocin and vasopressin. Neurosci Lett 76:209-214.

Dutton A, Dyball REJ (1979) Phasic firing enhances vasopressin release from the rat neurohypophysis. J Physiol (Lond) 290:433-440.

Dyball REJ (1988) The importance of bursting in determining secretory response: how does a phasic firing pattern influence peptide release from neurohypophysial vasopressin terminals. In: Pulsatility in neuroendocrine systems (Leng G, ed), pp 181-196. Boca Raton, FL: CRC.

Freund-Mercier M-J, Richard PH (1984) Electrophysiological evidence for the facilitatory control of oxytocin neurones by oxytocin during suckling in the rat. J Physiol (Lond) 352:447-466.

Hussy N, Deleuze C, Pantaloni A, Desarménien MG, Moos F (1997) Agonist action of taurine on glycine receptors in rat supraoptic magnocellular neurones: possible role in osmoregulation. J Physiol (Lond) 502:609-621.

Inenaga K, Yamashita H (1986) Excitation of neurones in the rat paraventricular nucleus in vitro by vasopressin and oxytocin. J Physiol (Lond) 370:165-180.

Inenaga K, Akamatsu N, Nagamoto T, Ueta Y, Yamashita H (1992) Intracellular EGTA alters phasic firing of neurons in the rat supraoptic nucleus in vitro. Neurosci Lett 147:189-192.

Kombian SB, Mouginot D, Pittman QJ (1997) Dendritically released peptides act as retrograde modulators of afferent excitation in the supraoptic nucleus in vitro. Neuron 19:903-912.

Lambert RC, Moos FC, Richard PH (1993) Action of endogenous oxytocin within the paraventricular or supraoptic nuclei: a powerful link in the regulation of the bursting pattern of oxytocin neurons during the milk-ejection reflex in rats. Neuroscience 57:1027-1038.

Leng G (1981) The effects of neural stalk stimulation upon firing patterns in the rat supraoptic neurones. Exp Brain Res 41:135-145.

Leng G, Wiersma J (1981) Effects of neural stalk stimulation on phasic discharge of supraoptic neurones in Brattleboro rats devoid of vasopressin. J Endocrinol 90:211-220.

Leng G, Mason WT (1982) Influence of vasopressin upon firing patterns of supraoptic neurons: a comparison of normal and Brattleboro rats. Ann NY Acad Sci 394:153-158.

Leng G, Dyball REJ (1983) Intercommunication in the rat supraoptic nucleus. Q J Exp Physiol 68:493-504.

Li Z, Hatton GI (1995) Calcium release from internal stores: involvement in generation of burst firing patterns in hypothalamic supraoptic neurons. J Gen Physiol 106:21-22.

Li Z, Hatton GI (1997) $\mathrm{Ca}^{2+}$ release from internal stores: role in generating depolarizing after-potentials in rat supraoptic neurones. J Physiol (Lond) 498:339-350.

Lincoln DW, Hill A, Wakerley JB (1973) The milk-ejection reflex of the rat: an intermittent function not abolished by surgical levels of anaesthesia. J Endocrinol 57:459-476.

Ludwig M, Callahan MF, Neumann I, Landgraf R, Morris M (1994) Systemic osmotic stimulation increases vasopressin and oxytocin release within the supraoptic nucleus. J Neuroendocrinol 6:369-373.

Ludwig M, Callahan MF, Morris M (1995) Effects of tetrodotoxin on osmotically stimulated central and peripheral vasopressin and oxytocin release. Neuroendocrinology 62:619-627.

Moos F, Richard PH (1989) Paraventricular and supraoptic bursting oxytocin cells in rat are locally regulated by oxytocin and functionally related. J Physiol (Lond) 408:1-18.

Moos FC, Rossi K, Richard PH (1997) Activation of $N$-methyl-Daspartate receptors regulates basal electrical activity of oxytocin and vasopressin neurons in lactating rats. Neuroscience 77:993-1002.

Neumann I, Ludwig M, Engelmann M, Pittman QJ, Landgraf R (1993) Simultaneous microdialysis in blood and brain: oxytocin and vasopressin release in response to central and peripheral osmotic stimulation and suckling in the rat. Neuroendocrinology 58:637-645.

Oliet SHR, Bourque CW (1993a) Steady-state osmotic modulation of cationic conductance in neurons of rat supraoptic nucleus. Am J Physiol 265:1475-1479.

Oliet SHR, Bourque CW (1993b) Mechanosensitive channels transduce osmosensitivity in supraoptic neurons. Nature 364:341-343.

Ota M, Crofton JT, Share L (1994) Hemorrhage-induced vasopressin release in the paraventricular nucleus measured by in vivo microdialysis. Brain Res 659:49-54.

Poulain DA, Wakerley JB (1982) Electrophysiology of hypothalamic magnocellular neurones secreting oxytocin and vasopressin. Neuroscience 7:773-808.

Poulain DA, Wakerley JB, Dyball REJ (1977) Electrophysiological differentiation of oxytocin- and vasopressin-secreting neurones. Proc R Soc Lond B Biol Sci 196:367-384.

Poulain DA, Brown D, Wakerley JB (1988) Statistical analysis of patterns of electrical activity in vasopressin and oxytocin-secreting neurones. In: Pulsatility in neuroendocrine systems (Leng G, ed), pp 119-154. Boca Raton, FL: CRC.

Pow DV, Morris JF (1989) Dendrites of hypothalamic magnocellular neurons release neurohypophysial peptides by exocytosis. Neuroscience 32:435-439.

Sabatier N, Richard PH, Dayanithi G (1997) L-, N- and T- but neither Pnor Q-type $\mathrm{Ca}^{2+}$ channels control vasopressin-induced $\mathrm{Ca}^{2+}$ influx in magnocellular vasopressin neurones isolated from the rat supraoptic nucleus. J Physiol (Lond) 503:253-268.

Shaw FD, Bicknell RJ, Dyball REJ (1984) Facilitation of vasopressin release from the neurohypophysis by application of electrical stimuli in bursts: relevant stimulation parameters. Neuroendocrinology 39:371-376.

Wakerley JB, Poulain DA, Dyball REJ, Cross BA (1975) Activity of phasic neurosecretory cells during haemorrhage. Nature 258:82-84.

Wakerley JB, Poulain DA, Brown D (1978) Comparison of firing patterns in oxytocin- and vasopressin-releasing neurones during progressive dehydration. Brain Res 148:425-440. 